International Justice Resource Center.

Access: http://www.ijrcenter.org.

As a nonprofit human rights organization, the International Justice Resource Center (IJRC) aims to educate and empower individuals to better understand their human rights as global citizens. Its website serves as the online hub of these efforts, offering visitors a central gateway for exploring a range of human rights issues and the tools to equip them to address violations of these rights.

Though not limited to these alone, IJRC's core services (and by extension, its website) can be roughly summarized as falling in three main areas: producing and distributing informational guides and other publications, offering training sessions for organizations, and providing litigation and advocacy support for groups and individuals alike.

Of particular note is the first area-especially IJRC's extensive overviews of human rights laws, its directories of the international courts and bodies that monitor them, and its accompanying research aids. Within these aids, visitors will also find IJRC's developing Thematic Research Guides-comprehensive primers outlining specific human rights (e.g., citizenship, education, asylum, immigration) and their associated oversight mechanisms and latest developments. IJRC also notably references a wealth of external resources of interest throughout their guides, including lists of related books and journals (many of which are open access), as well as online international databases for locating court decisions, jurisprudence, and current and pending cases.

The website also provides resources for staying up to date on recent global develop-

Joni R. Roberts is associate university librarian for public services and collection development at Willamette University, email: jroberts@willamette.edu, and Carol A. Drost is associate university librarian for technical services at Willamette University, email: cdrost@ willamette.edu ments through "News and Events" and a daily newsletter. However, the homepage itself essentially serves a similar purpose-visitors are immediately greeted there with a scrolling feed of news clips, monthly overviews, and upcoming sessions and meetings, which gives a feeling of immediacy and currency. Other resources of interest include its "Media and Publications" section, where visitors can download various manuals and even view videos of some of their prior training sessions.

Overall, the IJRC website is a helpful resource for those interested in researching the scope and current discussions surrounding human rights internationally. Its robust content effectively serves IJRC's central mission: enabling individuals' access to human rights information in order to educate and advocate for the ongoing protection and advancement of these rights.-Tarida Anantachai, Syracuse University Libraries, tanantac@syr.edu

PlayShakespeare.Com. Access: https:// www.playshakespeare.com/.

PlayShakespeare.Com offers free and open access to Shakespeare's works via the Internet. The website distributes, at current count, 41 plays, including some of contested authorship; 154 sonnets; and six poems under a GNU Free Documentation License, and the texts constitute an original edit on the part of the PlayShakespeare team, making them open source. The texts are derived primarily from the First Folio, the 1866 Globe Edition, various Quartos, and other sources. PlayShakespeare permits users to use their texts in a wide variety of ways, including for performance. The website also distributes two apps, one free and one paid, that offer access to the same texts as the website.

Each play is accompanied by a synopsis, list of characters, display of individual scenes, and a full version of the play, as well as the text of Quartos used in the edit of said play, access to theatrical reviews 
made by members of the PlayShakespeare team, foreign language translations, and audio recordings. In order to download full versions, Quartos, translations, or audio, users must register for free with the website. All other material is accessible with or without registration.

Those conducting Shakespeare scholarship may find the various Quarto texts helpful, though the scholarship of the full versions offered by the website is unclear. Information on who edited each text has not been made openly available, and the PlayShakespeare team is comprised of many people: a couple are literary scholars and some, including the editor-in-chief, are professional theater artists, but many are listed as being theater reviewers, and the credentials of others are nebulous. A chart offered by the website showing which sources were used in the creation of each text is very helpful.

Those looking for free versions of Shakespeare's works for personal study, remixing and preparing derivative works, or even production, might find this to be a valuable website, and the mobile app may heighten that appeal. Those considering a resource for classroom use instead may want to look at the Folger Digital Library, which offers the texts of the Folger Shakespeare Library editions free of charge under a Creative Commons license. Those texts have been edited by recognized scholars in the field, and are accompanied by digital images, teaching and learning resources, and more.-Patrick Woblmut, Linfield College, pwohlmut @linfield.edu

\section{U.S. Fish and Wildlife Service: Endangered}

Species. Access: https://www.fws.gov /endangered/index.html.

The Endangered Species site from the U.S. Fish and Wildlife Service is a portal for just about everything anyone might need to know about the Endangered Species Act (ESA). This review focuses on two sections particularly useful to academic librarians: the site's "Laws and Policies" section and database of endangered species.
The "Laws and Policies" section is a resource for legal references and government documents about endangered species. This section includes the entire text of the ESA, a history of the ESA, links to regulations and policies related to the ESA issued by the U.S. Fish and Wildlife Service and the National Marine Fisheries Service, and links to notices related to the ESA published in the Federal Register.

The database of endangered species lets users access the Fish and Wildlife Service's profiles on animals and plants protected under the ESA. Users access this database through the search options on the main Endangered Species page or the "Species Search/Map" link found in the "Species" menu. Either way provides similar ways to search the database: by geographic location (state or county) or by name (common or scientific).

These profiles are not biological or zoological, but rather are a place to find all the laws, policies, and other documents applicable to an animal or plant under the ESA. Each profile starts with a species' scientific and common names, its status (endangered, threatened, or several others), and a map of where it can be found in the United States.

The rest of the profile comprises links to documents about the species related to its protected status, including any petitions to update its status, documents from the Federal Register mentioning the species, reports on the species' habitat, and plans to help the species recover or to conserve its habitat.

The information on the site appears to be relatively current. The main page, "Laws and Policies" page, and "Species Search/Map" page have been updated in the last three months. Each link on the "Laws and Policies" page and on the species profiles notes the date of the document to which it leads. Species profiles, however, do not have "last updated" dates.

This site will be of interest to students in the natural sciences. - C. Jeff Lacy, Trinity University, clacy@trinity.edu $\approx$. 